\title{
A cat scratch disease case presenting with underarm painful lymphadenopathy
}

\author{
Bulent Yardimci \\ Associate Professor, Department of Internal Medicine, Istanbul American Hospital, Istanbul, Turkey
}

Cat Scratch Disease (CSD) or Cat Scratch Fever (CSF) is an infectious disease that typically begins as a cutaneous lesion and causes proximal regional lymph nodes enlargement. In general, it is infected as a result of cat saliva and scratches. It rarely causes systemic manifestations. Since it may be observed worldwide, the differential diagnosis should be strictly introduced in case of local lymphadenopathies.

Key words: Cat scratch disease; Cat scratch fever; Lymphadenopathy; Local lymphadenopathy

\section{Access this article online}

Website:

http://nepjol.info/index.php/AJMS DOI: 10.3126/ajms.v13i2.42215

E-ISSN: 2091-0576

P-ISSN: 2467-9100

Copyright (c) 2022 Asian Journal of Medical Sciences

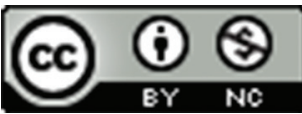

This work is licensed under a Creative Commons Attribution-NonCommercial 4.0 International License.

\section{INTRODUCTION}

Cat Scratch Disease (CSD) is a disease that is caused, for the most part, by Bartonella henseale and progresses with local lymphadenopathy. The disease generally restricts itself and remains as local lymphadenopathy. It may also cause visceral organ involvement, mainly in elders and immunosuppressive patients. ${ }^{1,2} B$. henseale is found in cat erythrocytes and cat fleas (Ctenocephalides felis). Fleas are considered to be the most important factor for inter cat contamination. Fleas may also infect humans with this disease. However, the bacteria exist in cat saliva and is generally infect humans with cat bites and scratches. ${ }^{2}$

\section{CASE PRESENTATION}

A 35-years-old female patient; applied to our outpatient clinic of internal diseases with the complaint of swelling and pain at the right underarm for 2 weeks. She did not define any other symptoms accompanying this complaint, for example., fever, fatigue, sweating, etc. During her examination erythema under her right wrist was found. She did not recall having any severe injuries that could cause the erythema.

Her arterial blood pressure was 120/60 $\mathrm{mmHg}$, pulse: $76 /$ min. regular and temperature: $36.8^{\circ} \mathrm{C}$. At her right underarm, painless lymphadenopathies of soft consistency were determined. There was a small skin lesion at her right wrist (Figure 1). The other systemic findings were normal.

In laboratory analysis, the results were determined as follows: CRP: $1.7 \mathrm{mg} / \mathrm{L}$, leukocyte: $10.36 \mathrm{~K} / \mathrm{uL}$, hemoglobin: $12.3 \mathrm{~g} / \mathrm{dL}$, hematocrit: $36 \%$, thrombocyte: $372 \mathrm{~K} / \mathrm{uL}$ Speed of sedimentation: $28 \mathrm{~mm} / \mathrm{h}$.

In USG taken from the underarm, lymph glands of granulomatous nature were observed. The radiologic image is seen in Figure 2. 
The patient was contacted again after laboratory results. The patient remembered that she got scratched by a street cat she was petting and her hand bled after the scratch. She said that her wrist was swollen and itchy, so she scratched it which caused more bleeding. She further said that she forgot this incident and that the wound on her wrist may have resulted from this.

Based on this narrative, the patient's $B$. henseale antibodies were requested. She was administered $500 \mathrm{mg}$ of Azitromisin tablet for the $1^{\text {st }}$ day and for the following 5 days $250 \mathrm{mg}$ a day. As a result of the patient's analysis which came out 3 weeks later, $B$. henselae $\operatorname{IgM}$ antibody was found to be 1:100, $B$. henselae $\operatorname{IgG}$ antibody 1:2560, and cat scratch fever was diagnosed.

The patient's underarm pain stopped at the end of the first 3 weeks and her lymphadenopathy disappeared after 2 months.

\section{DISCUSSION}

$B$. henselae, which is the cause of the disease, is a gramnegative bacillus. Generally, B. henseale's types Houston-1 and Meseille, which are seen in humans and cats, cause the disease. ${ }^{2} B$. henseale pervades the endothelial cells and activates the proinflammatory cascade. Thus, acute inflammatory reaction occurs. This reaction, which is usually local, may spread in certain people and cause a disseminated disease.

The disease is more common in young cats and a major part of these cats has a healthy appearance. A very small percentage of the patients would not remember the cat scratches. Our patient has remembered in the second inquiry, which was made after the first examination results, that she has petted a young street cat and that the cat has scratched her hand to an extent that made it bleed. At this point, the significance of history taking becomes evident once more. No matter which advanced techniques we use, a good anamnesis maintains its importance in determining which analysis, among many others, we shall prefer.

Generally, primary skin lesion begins on the area which is bitten or scratched by the cat in the form of a vesicle. In 1-2 weeks, a local lymphadenopathy evolves. The disease is frequently seen in children and young adults. Lymphadenopathy is generally painful, sensitive, and suppurative. In $75 \%$ of the patients, other symptoms like fatigue, anorexia, and in 9\% fever occur. ${ }^{2,3}$ In our patient's case, the clinical manifestation consisted of local painful lymphadenopathy, rather than systematic effects.
CSD turns into a local disease in $85-90 \%$ of the cases and may also cause a severe systemic disease. It may cause spleen, liver, eye, and central nervous system manifestations. It may also be the cause of neuroretinitis, papillitis, optic neuritis, encephalopathy, transverse myelitis cerebellar ataxia, and radiculitis. Rarely, it may cause pneumonia, endocarditis, and septic shock. Encephalitis and endocarditis are seen usually in patients over 60 years of age. In cases with encephalitis, endocarditis and fever of unknown origin caused by $B$. henseale, diagnosis may be delayed by more than 6 weeks. ${ }^{4,5}$

The diagnosis is established serologically by means of the indirect fluorescence assay (IFA) and enzyme immunosorbent assay (EIA) methods. If the IFA $\operatorname{IgG}$ titer is $<1: 64$, then Bartonella infection is not considered. If titers $>256$, it suggests a strongly active or recently undergone infection. On the other hand, positive IFA IgM suggests strongly acute infection since this antibody remains transiently high. Due to the fact that it is very difficult to isolate $B$. henselae from culture and tissues, it is generally not applied in daily practice. $^{2}$

The lymph gland biopsy made on patients, whose diagnosis could not be established, is not specific. However, it is substantial especially in the differential diagnosis of malignant diseases such as lymphoma. Our patient had also come to our hospital primarily with the concern of lymphoma or leukemia.

In the case of this patient, the diagnosis was established by means of ultrasonography and serologic analysis made following the anamnesis and clinical indications. Any interventional operation such as lymph gland biopsy has not been made.

Especially in one-sided lymphadenopathies, infectious causes except for lymphoma and leukemia, such as cytomegalovirus lymphadenopathy, EbsteinBarr virus lymphadenopathy, human immunodeficiency virus lymphadenopathy, nontuberculosis mycobacterial lymphadenitis, Staphylococcus aureus adenitis, and toxoplasmosis lymphadenopathy are considered as differential diagnosis. ${ }^{3}$

The treatment varies according to the penetration of the disease. Due to its recovery after having progressed as a self-limited disease, generally between 2 and 8 weeks, especially in case of children, it does not require any treatment. The agent used for mild and moderate diseases is azithromycin with a daily dose of $500 \mathrm{mg}$ for 5 days and then $250 \mathrm{mg}$ for 4 days. Rifampin, ciprofloxacin, 


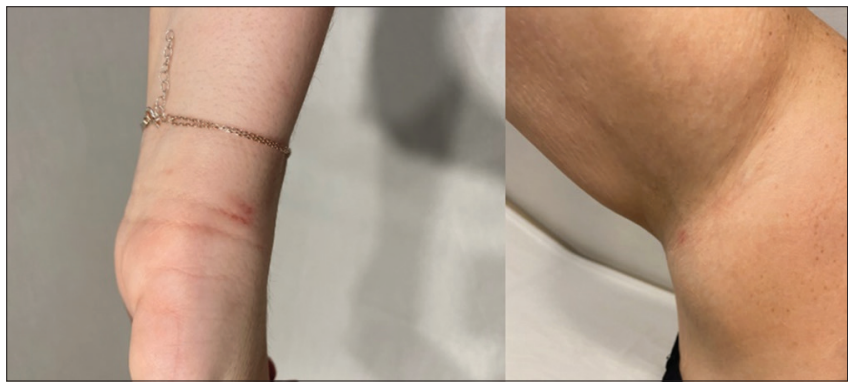

Figure 1: Photograhies of small skin lesion at her right wrist and right underarm lymph nodes enlargements

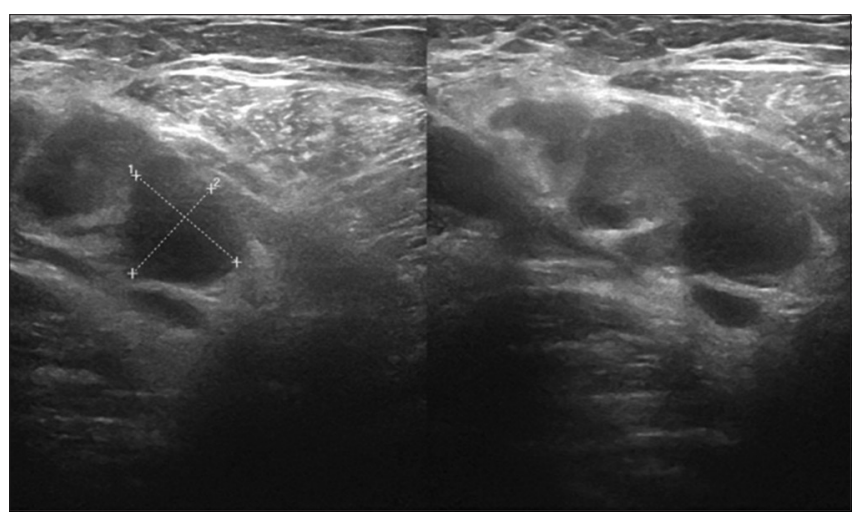

Figure 2: Lymph glands of granulomatous nature is seen in patient's underarm ultrasonography

gentamicin, and trimethoprim/sulfamethoxazole are other antibiotics used., ${ }^{2,3}$ In case of this patient, a good result has been achieved by means of the azithromycin treatment.

\section{CONCLUSION}

CSD is a disease that may be observed worldwide and which should be taken into consideration in the differential diagnosis in local lymphadenopathies. Diagnosis may be established by taking the patients' history well, together with physical examination and serologic analysis. In case of questionable cases, lymph gland biopsy may be performed as well. The fact that bacteria cannot be reproduced easily in culture and that biopsy results are not always specific are the difficulties in the diagnosis.

\section{REFERENCES}

1. Gai M, d'Onofrio G, di Vico M C, Ranghino A, Nappo A, Diena D, et al. Cat-scratch disease: Case report and review of the literature. Transplant Proc. 2015;47(7):2245-2247.

https://doi.org/10.1016/j.transproceed.2015.07.014

2. Spach DH and Kaplan SL. Microbiology, Epidemiology, Clinical Manifestations, and Diagnosis of Cat Scratch Disease; 2021. Available from: https://www.uptodate.com/contents/microbiologyepidemiology-clinical-manifestations-and-diagnosis-of-catscratch-disease [Last accessed on 2021 Nov 01].

3. Klotz SA, lanas V and Elliott SP. Cat-scratch disease. Am Fam Physician. 2011;83(2):152-155.

4. Umbreen $G$ and Jabeen $C$. Case reports of cat scratch disease with typical and atypical clinical manifestations: A literature review. Int J Med Res Health Sci. 2017;6(4):51-54.

5. Nawrocki CC, Max RJ, Marzec NS and Nelson CA. Atypical manifestations of cat-scratch disease, United States, 20052014. Emerg Infect Dis. 2020;26(7):1438-1446.

https://doi.org/10.3201/eid2607.200034

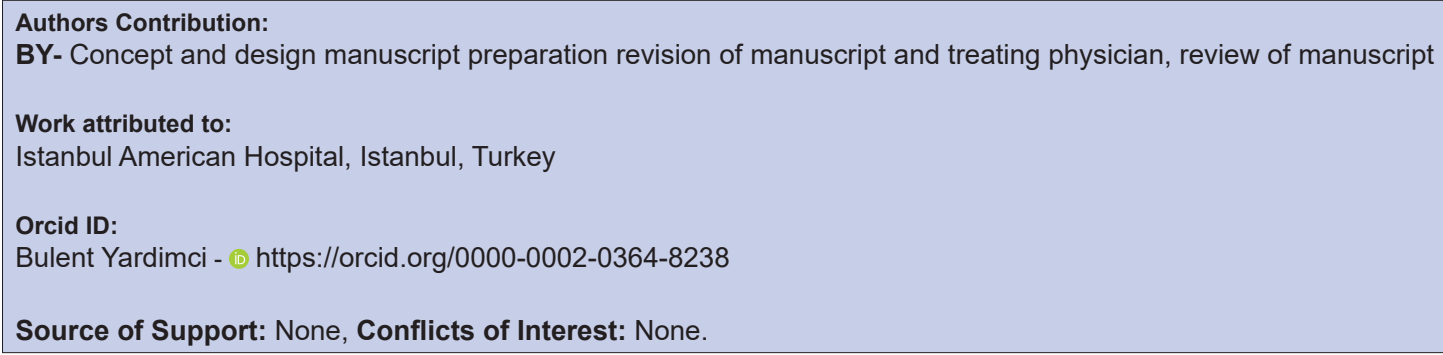

